\title{
Increased interleukin-17A levels promote rituximab resistance by suppressing p53 expression and predict an unfavorable prognosis in patients with diffuse large $B$ cell lymphoma
}

\author{
WEIJIE ZHONG ${ }^{1,2}$, XIN XU $^{2,3}$, ZHIGANG ZHU ${ }^{2}$, LI YANG $^{4,5}$, HONG DU $^{6}$, ZHONGJUN XIA $^{5}$, \\ ZHAOHU YUAN ${ }^{7}$, HUABAO XIONG $^{3}$, QINGHUA DU ${ }^{4}$, YAMING WEI $^{1,7}$ and QINGSHAN LI ${ }^{1,4}$ \\ ${ }^{1}$ The First Affiliated Hospital, Jinan University, Guangzhou, Guangdong 510630; ${ }^{2}$ Department of Geriatrics, \\ Hematology and Oncology Ward, Guangzhou First People's Hospital, Guangzhou Medical University, Guangzhou, \\ Guangdong 510180, P.R. China; ${ }^{3}$ Immunology Institute, Icahn School of Medicine at Mount Sinai, New York, \\ NY 10029-5674, USA; ${ }^{4}$ Department of Hematology, Guangzhou First People's Hospital, Guangzhou Medical University, \\ Guangzhou, Guangdong 510180; ${ }^{5}$ Collaborative Innovation Center for Cancer Medicine, \\ State Key Laboratory of Oncology in South China, Department of Hematological Oncology, \\ Sun Yat-Sen University Cancer Center, Guangzhou, Guangdong 510060; \\ Departments of ${ }^{6}$ Pathology and ${ }^{7}$ Blood Transfusion, Guangzhou First People's Hospital, \\ Guangzhou Medical University, Guangzhou, Guangdong 510180, P.R. China
}

Received November 22, 2017; Accepted February 23, 2018

DOI: $10.3892 /$ ijo.2018.4299

\begin{abstract}
Rituximab resistance has become increasingly common in patients with diffuse large B cell lymphoma (DLBCL). However, the mechanisms involved remain unclear. In this study, we aimed to examine the effect of rituximab on interleukin (IL)-17A and to investigate the role of IL-17A in rituximab resistance and its prognostic value in patients with DLBCL. Our retrospective analysis revealed that rituximab increased IL-6 expression levels in patients with DLBCL, and the increased IL-6 levels in turn induced the differentiation of Th17 and IL- $17^{+}$Foxp $3^{+}$Treg cells, which secreted IL-17A both in vivo and in vitro. We then examined the effects of IL-17A on the apoptosis and proliferation of, and p53 expression in DLBCL cells, and found that IL-17A prevented rituximab-induced apoptosis and promoted the proliferation of DLBCL cells by suppressing p53 expression in vitro. The survival data of 73 patients with DLBCL suggested that high peripheral blood levels of
\end{abstract}

Correspondence to: Dr Qingshan Li, Department of Hematology, Guangzhou First People's Hospital, Guangzhou Medical University, 1 Panfu Road, Guangzhou, Guangdong 510180, P.R. China

E-mail: drliqingshang@126.com

Dr Yaming Wei, Department of Blood Transfusion, Guangzhou First People's Hospital, Guangzhou Medical University, 1 Panfu Road, Guangzhou, Guangdong 510180, P.R. China

E-mail: weiyaming@163.com

Key words: interleukin-17A, rituximab resistance, p53 protein, lymphoma, large B cell, diffuse
IL-17A predicted an unfavorable survival. On the whole, our data indicate that rituximab promotes Th17 and IL- $17^{+}$Foxp $3^{+}$ Treg cells to secrete IL-17A, which in turn promotes rituximab resistance, partially by suppressing p53 expression and inhibiting rituximab-induced DLBCL cell apoptosis. IL-17A may thus prove to be a useful prognostic marker in patients with DLBCL.

\section{Introduction}

Diffuse large B cell lymphoma (DLBCL) is a common and highly aggressive and heterogeneous subtype of non-Hodgkin's lymphoma (NHL), which accounts for almost $40 \%$ of all NHL cases (1). Despite combined chemotherapy, patients with DLBCLs still have a 5-year mortality rate of approximately $50 \%$ (2). Rituximab is an anti-CD20 mouse-human chimeric monoclonal antibody, which is known to exert a good curative effect in patients with DLBCL. Rituximab combined with cyclophosphamide, adriamycin, vincristine and prednisone (R-CHOP) is currently the standard first-line treatment regimen for patients with DLBCL, resulting in complete remission in approximately $80 \%$ of patients $(3,4)$. However, the widespread clinical use of rituximab has been associated with increasing rituximab resistance (RR) in patients with DLBCL, and previous studies have revealed that $30 \%$ of cases are resistant to rituximab or rituximab-based chemotherapeutic regimens $(5,6)$. Furthermore, as previously demonstrated, $60 \%$ of patients with lymphoma who previously responded to rituximab failed to derive benefit when treated with rituximab again, as a result of acquired drug resistance (7). Although some studies have investigated the pathogenesis of RR (5-9), the underlying mechanisms remain incompletely understood. It is therefore crucial to explore the mechanisms responsible 
for RR in order to improve the therapeutic outcomes of patients with DLBCL.

Interleukin (IL)-17A, a member of the IL-17 family (IL-17A-F), is an inflammatory cytokine that protects the body from bacterial and fungal infections by recruiting neutrophils to the site of inflammation (10). IL-17A exerts its effects by binding to the IL-17 receptor (IL-17R) (11). IL-17A is mainly secreted by $\mathrm{T}$ helper (Th) 17 cells, and the process is enhanced by IL-6 combined with transforming growth factor (TGF)- $\beta$ (12). $\mathrm{CD}^{+} \mathrm{T}$ cells exhibit considerable plasticity in terms of the differentiation and development of Th1/Th2, Th1/ Th17 and Th17/regulatory T (Treg) cells (13). IL-17+Foxp3 ${ }^{+}$ Treg cells comprise a novel subtype of $\mathrm{CD} 4^{+} \mathrm{T}$ cells that secrete IL-17A, representing an intermediate differentiation stage between Th17 and Treg cells (14). IL-17 ${ }^{+}$Foxp $3^{+}$Treg cells have recently been shown to promote the growth of esophageal and colon cancers $(15,16)$.

DLBCL is known to be associated with cytokines in the tumor microenvironment (17). Th17 cells and IL-17A play important roles in tumor immune regulation in NHL, and Yang et al found that the development of Th17 cells and IL-17A was significantly decreased in the tumor microenvironment in patients with NHL (18). Furthermore, a recent study indicated that the frequency of Th17 cells and IL-17A levels in peripheral blood (PB) were markedly lower in patients with DLBCL compared with healthy individuals, and the differentiation of circulating Th17 cells increased in relapsed patients with DLBCLs (19). Another study verified that IL-17A promoted the growth of human germinal center-derived NHL, including DLBCL (20). We have previously demonstrated that irradiated NHL cells (k1106 cells) promoted Foxp $3^{+}$Treg cells to secrete IL-17 by increasing the secretion of IL-6; secreted IL-17 then inhibited the irradiated-induced apoptosis of NHL cells by suppressing p53 (21). IL-17A is thus a pro-tumor factor in DLBCL.

Recently, published data have indicated that the therapeutic use of kinase inhibitors targeting B-Raf proto-oncogene, serine/threonine kinase (BRAF), ALK receptor tyrosine kinase (ALK) or epidermal growth factor receptor (EGFR) induces secretomes, which contribute to drug resistance (22). Some studies have also shown that serum IL-6 levels in patients with NHL are elevated in vivo by rituximab-based chemotherapeutic regimens $(23,24)$. IL-6 is known to promote the differentiation of Th17 cells, which secrete IL-17A. Thus, we hypothesized that rituximab may induce secretomes, such as IL-17A and IL-6, to promote RR in patients with DLBCL, although the mechanisms through which rituximab affects IL-17A secretion remain to be elucidated.

In the present study, our aim was to examine the effects of rituximab on IL-17A and to investigate the role of IL-17A in RR and its prognostic value in patients with DLBCL. We retrospectively analyzed the effects of rituximab on Th17 and IL- $17^{+}$Foxp $3^{+}$Treg cell differentiation, and IL-17A and IL-6 secretion in patients with DLBCL and in SU-DHL-4 cell co-cultures in vitro. IL-17 receptor knockdown and wild-type SU-DHL4 cells were cultured with rituximab and IL-17A, respectively, to determine the effects of IL-17A on apoptosis, proliferation and $\mathrm{p} 53$ expression. We also analyzed the survival of 73 patients with DLBCL in order to evaluate the prognostic value of IL-17A.

\section{Materials and methods}

Reagents. Antibodies against IL-6, p53 and IL-17R were purchased from Santa Cruz Biotechnology (Santa Cruz, CA, USA). Human recombinant IL-6 (Cat. no. 206-IL) and IL-17A (Cat. no. 7955-IL), and human neutralizing antibodies to IL-6 (aIL-6) (Cat. no. AF-206-NA) and IL-17A (aIL-17A) (Cat. no. AF-317-NA) were obtained from R\&D Systems (Minneapolis, MN, USA). Enzyme-linked immunosorbent assay (ELISA) kits for IL-17A, IL-6, IL-21 and TGF- $\beta$ were purchased from BioLegend (San Diego, CA, USA). Fluorescence-activated cell sorting (FACS) human antibodies, including anti-CD3-phycoerythrin (PE)-Cy7 (Cat. no. 557851), anti-CD8-allophycocyanin (Cat. no. 561952), anti-CD4-fluorescein isothiocyanate (Cat. no. 561005), antiFoxp3-PE (Cat. no. 560852), anti-IL-17A-PE (Cat. no. 560436), anti-IL-17A-PE-Cy7 (Cat. no. 560799) and their matched antimouse IgG1 K-PE (Cat. no. 551436)/PE-Cy7 (Cat. no. 552811) were all purchased from BD Biosciences (San Jose, CA, USA). Reverse transcription-quantitative polymerase chain reaction (RT-qPCR) reagents were obtained from Takara (Beijing, China). Rituximab was purchased from Novartis (Basel, Switzerland).

Patients and sample collection. This study included 113 patients newly diagnosed with DLBCL from January 2010 to December 2016 at Guangzhou First People's Hospital, Guangzhou Medical University, and Sun Yat-Sen University Cancer Center (Guangzhou, China). All patients with DLBCL were diagnosed by experienced pathologists and the diagnosis was consistent with DLBCL diagnostic criteria. In addition, 20 healthy individuals were selected as the controls. We collected PB samples from all 113 patients and the 20 controls prior to treatment, which were designated as the DLBCL group (untreated group, $n=113$ ) and the Ctrl group $(n=20)$. All the patients were then treated with an R-CHOP or R-CHOP-like regimen (rituximab, cyclophosphamide, doxorubicin, vincristine and prednisone), or with a $\mathrm{CHOP}$ or $\mathrm{CHOP}$-like regimen. Further PB samples were collected after 2-4 cycles and the curative effects were evaluated as complete remission (CR) or no complete remission (NCR). The 113 patients were then divided into 4 groups according to their chemotherapeutic regimens and curative effects: The CHOP-CR group $(n=25)$, CHOP-NCR group $(n=15)$, R-CHOP-CR group $(n=56)$ and R-CHOP-NCR group ( $n=17)$. With the inclusion of the Ctrl group and the DLBCL group (untreated group, before treatment), in total, there were 6 groups in this study. The baseline clinical characteristics of all the groups are listed in Table I. The survival data of the 73 patients treated with the R-CHOP regimens were collected through phone calls or clinical visits. Survival time was defined as the period from diagnosis to the last visit, relapse or death. This study was approved by the Ethics Committee of Guangzhou First People's Hospital (2014-SYL-034). Written informed consent was obtained from all participants or their families prior to obtaining the samples.

Cell lines and cell culture. The SU-DHL-4 cell line was purchased from ATCC (Manassas, VA, USA) and cultured in RPMI-1640 medium (HyClone, South Logan, UT, USA) containing $10 \%$ fetal bovine serum (FBS) (HyClone), 
Table I. Baseline clinical characteristics of the patients with DLBCL and the healthy individuals.

\begin{tabular}{|c|c|c|c|c|c|c|}
\hline \multirow[b]{2}{*}{ Variable } & \multicolumn{5}{|c|}{ Patients with DLBCL } & \multirow{2}{*}{$\frac{\text { Healthy individuals }}{\text { Ctrl }}$} \\
\hline & DLBCL & CHOP-CR & CHOP-NCR & R-CHOP-CR & R-CHOP-NCR & \\
\hline \multicolumn{7}{|c|}{ Age (years) } \\
\hline$<50$ & 43 & 10 & 7 & 19 & 7 & 7 \\
\hline$\geq 50$ & 70 & 15 & 8 & 37 & 10 & 13 \\
\hline P-value ${ }^{a}$ & 0.957 & & & & & \\
\hline \multicolumn{7}{|l|}{ Sex } \\
\hline Male & 66 & 14 & 10 & 31 & 11 & 14 \\
\hline Female & 47 & 11 & 5 & 25 & 6 & 6 \\
\hline P-value & 0.849 & & & & & \\
\hline \multicolumn{7}{|c|}{ Ann Arbor stage ${ }^{b}$} \\
\hline I-II & 45 & 9 & 6 & 22 & 8 & I \\
\hline III-IV & 68 & 16 & 9 & 34 & 9 & l \\
\hline P-value ${ }^{a}$ & 0.970 & & & & & \\
\hline \multicolumn{7}{|l|}{ IPI score ${ }^{c}$} \\
\hline $1-3$ & 64 & 13 & 10 & 29 & 12 & 1 \\
\hline $4-5$ & 49 & 12 & 5 & 27 & 5 & 1 \\
\hline P-value ${ }^{a}$ & 0.606 & & & & & \\
\hline
\end{tabular}

DLBCL, diffuse large B cell lymphoma; CHOP-CR, patients treated with CHOP regimens and who had complete remission; CHOP-NCR, patients treated with $\mathrm{CHOP}$ regimens and who had no complete remission; R-CHOP, rituximab and CHOP. ${ }^{\mathrm{a}} \mathrm{Chi}-\mathrm{square}$ test; ${ }^{\mathrm{b}} \mathrm{Ann}$ Arbor stage according to Ann Arbor-Cotswald staging (1989). 'IPI score, International Prognostic Index score.

4 mM L-glutamine (Sigma-Aldrich, St. Louis, MO, USA), $100 \mathrm{U} / \mathrm{ml}$ of penicillin (HyClone), and $100 \mathrm{U} / \mathrm{ml}$ of streptomycin (HyClone). 293T cells were purchased from ATCC and cultured in Dulbecco's modified Eagle's medium (HyClone) supplemented with $10 \%$ FBS. All the cells were cultured in a humidified chamber at $37^{\circ} \mathrm{C}$ with an atmosphere of $5 \% \mathrm{CO}_{2}$.

Cell cultures in vitro. We conducted 4 cell culture experiments in vitro. All the experiments were carried out using SU-DHL-4 cells and PB mononuclear cells (PBMCs) at $2 \times 10^{6}$ cells/well. PBMCs were isolated using the Ficoll-Hypaque method.

Experiment 1 . The SU-DHL-4 cells were cultured with various concentrations of rituximab $(0.0,0.1,1.0,10.0$ and $100.0 \mu \mathrm{g} /$ $\mathrm{ml}$ ) in a 6-well plate, and then incubated for $72 \mathrm{~h}$. The IL-6 mRNA and protein levels were analyzed by RT-qPCR), and by ELISA and western blot analysis, respectively.

Experiment 2. The PBMCs from the healthy donors were cultured in T cell medium containing 10\% FBS and $100 \mathrm{IU} / \mathrm{ml}$ human IL-2 (HyClone) in a 48-well plate, and stimulated with OKT3 $(1 \mu \mathrm{g} / \mathrm{ml}$, HyClone). The cells were then divided into 7 groups as follows: PBMCs alone; PBMCs $+100 \mu \mathrm{g} / \mathrm{ml}$ rituximab; PBMCs + rituximab $+1 \mu \mathrm{g} / \mathrm{ml}$ IL-6; PBMCs + SU-DHL-4 cells; PBMCs + rituximab + SU-DHL-4 cells; PBMCs + rituximab + SU-DHL-4 + IL-6; and PBMCs + rituximab + SU-DHL-4 + $1 \mu \mathrm{g} / \mathrm{ml}$ aIL-6. All the groups of cells were incubated for $72 \mathrm{~h}$ and then detected by ELISA and FACS analysis.

Experiment 3. This included 6 groups of cells cultured for $72 \mathrm{~h}$ as follows: SU-DHL- 4 cells alone; SU-DHL- $4+100 \mu \mathrm{g} / \mathrm{ml}$ rituximab; SU-DHL-4 + rituximab + PBMCs; SU-DHL-4 cells + rituximab + PBMCs + $1 \mu \mathrm{g} / \mathrm{ml}$ aIL-17A; SU-DHL-4 cells + rituximab $+1 \mu \mathrm{g} / \mathrm{ml}$ IL-17A; and SU-DHL-4 cells + IL-17A.

Experiment 4. IL-17 receptor knockdown (IL-17R-KD) and wild-type SU-DHL4 cells were cultured with $100 \mu \mathrm{g} / \mathrm{ml}$ anti-CD20 monoclonal antibody in the presence of various concentrations of IL-17A $(0-10 \mathrm{ng} / \mathrm{ml})$. The cells were then collected and analyzed by FACS analysis and Cell Counting kit-8 (CCK-8) assay.

Cell viability assay. Cell viability was assessed by CCK- 8 assay (Dojindo Laboratories, Kumamoto, Japan). Each sample was allocated in 6 wells and CCK- 8 was added $4 \mathrm{~h}$ before the end of the culture time. Wells without cells were set as the blank controls. The absorbance at $450 \mathrm{~nm}$ was measured using a Universal Microplate Spectrophotometer (Thermo Fisher Scientific, Inc., Waltham, MA, USA). The relative proliferation rate (\%) of the SU-DHL-4 cells was calculated as follows: [optical density of cancer cell lines at 450 (OD450) with IL-17A/OD450 of cancer cell lines without IL-17A] x100\%.

$R T-q P C R$. Total RNA was isolated from the cells using TRIzol reagent (Takara) according to the manufacturer's instructions. RNA was reverse transcribed into cDNA using PrimeScript RT Master Mix (Takara) according to the manufacturer's instructions. qPCR was performed using SYBR Premix Ex Taq II (Tli RNase H Plus) (Takara) on a LightCycler 480II system (Roche, Mannheim, Germany). The levels of IL-6 and p53 were normalized to those of glyceraldehyde-3-phosphate dehydrogenase (GAPDH). The primers $\left(5^{\prime} \rightarrow 3^{\prime}\right)$ used for qPCR 
wereasfollows:IL-6forward,ACTTCGTGCATGACTTCAGC and reverse, TCTTTGTTGGAGGGTGAGGG; p53 forward, TGGCCATCTACAAGCAGTCA and reverse, GGTACAGTC AGAGCCAACCT; and GAPDH forward, GCACCGTCAAGG CTGAGAAC and reverse, TGGTGAAGACGCCAGTGGA. The thermocycling conditions were as follows: Initial denaturation $94^{\circ} \mathrm{C}$ for $5 \mathrm{~min}$, denaturation $94^{\circ} \mathrm{C}$ for $15 \mathrm{sec}$, annealing $59^{\circ} \mathrm{C}$ for $30 \mathrm{sec}$, extension $72^{\circ} \mathrm{C}$ for $2 \mathrm{~min} 55 \mathrm{sec}$, and then run for 35 cycles.

Western blot analysis. The cells were lysed using sodium dodecyl sulfate buffer containing proteinase inhibitors (Roche). Equal amounts of protein $(50 \mu \mathrm{g})$ were separated by $10 \%$ sodium dodecyl sulfate-polyacrylamide gel electrophoresis and transferred onto polyvinylidene difluoride membranes (Bio-Rad Laboratories, Shanghai, China). The membranes were blocked and incubated with antibodies against GAPDH (dilution 1:200, Cat. no. sc-47724), IL-6 (1:200, Cat. no. sc-65327), p53 (1:200, Cat. no. sc-47698) and IL-17R (1:100, Cat. no. sc-376374) overnight at $4^{\circ} \mathrm{C}$. Antibodies against GAPDH, IL-6, p53 and IL-17R were purchased from Santa Cruz Biotechnology. The membranes were then incubated with horseradish peroxidaselabeled secondary antibody (1:500, Cat. no. sc-2031) (Santa Cruz Biotechnology). The protein bands were visualized using an enhanced chemiluminescence reagent.

Flow cytometry. The frequencies of Th17 cells and IL- $17^{+} \mathrm{Foxp}^{+}$Treg cells were detected by flow cytometry. Cell density was adjusted to $2 \times 10^{6} / \mathrm{ml}$. For the Th17 cells, the cells were stimulated by the addition of $50 \mathrm{ng} / \mathrm{ml}$ phorbol myristate acetate, $1 \mu \mathrm{g} / \mathrm{ml}$ ionomycin and $10 \mu \mathrm{g} / \mathrm{ml}$ Brefeldin A to the medium for $5 \mathrm{~h}$ at $37^{\circ} \mathrm{C}$ and $5 \% \mathrm{CO}_{2}$. The cells were then stained with fluorescence-labeled anti-CD3, anti-CD8 and anti-IL-17A antibodies for $1 \mathrm{~h}$ at room temperature. For the $\mathrm{IL}-17^{+} \mathrm{Foxp} 3^{+}$ Treg cells, the cells were stained with fluorescence-labeled anti-IL-17A, anti-CD4, and anti-Foxp3 antibodies for $1 \mathrm{~h}$ at room temperature. The cells were then analyzed using a flow cytometer (FACSCanto II; BD Biosciences) and the data were analyzed with FlowJo software. $\mathrm{CD}^{+} \mathrm{CD} 8 \mathrm{IL}^{-17 \mathrm{~A}^{+} \text {cells were }}$ defined as Th17 cells, and CD4 ${ }^{+} \mathrm{IL}-17 \mathrm{~A}^{+}$Foxp $3^{+}$cells were defined as IL- $17^{+}$Foxp $3^{+}$Tregs.

ELISA. Serum from patient PB or the supernatants from cell cultures were assessed for IL-17A, IL-21, IL- 6 and TGF- $\beta$ levels by ELISA, following the manufacturer's instructions.

Knockdown of IL-17R expression in SU-DHL-4 cells. IL-17Rspecific short hairpin RNAs (shRNAs) were delivered by lentiviral infection to knock down IL-17R expression in the SU-DHL cells. The RNAi Consortium human IL-17R shRNA and Trans-Lentiviral shRNA Packaging kit with Calcium Phosphate Transfection Reagent (including pGIPZ ${ }^{\mathrm{TM}}$ Non-silencing Control Vector DNA) were purchased from Dharmacon (Lafayette, CO, USA). The IL-17R shRNA sequence was $\left(5^{\prime} \rightarrow 3^{\prime}\right)$ GGCTAAACTGCACGGTCAAGAC. The IL-17R-specific shRNA was cloned into the pLKO.1 puro plasmids. Briefly, the 293T cells were seeded at a density of $5.5 \times 10^{6}$ cells $/ 14 \mathrm{ml}$ in a $100-\mathrm{mm}$ plate, as described in our previous study (25). The following day, $42 \mu \mathrm{g}$ shRNA plasmid was transfected into the $293 \mathrm{~T}$ cells, together with $30 \mu \mathrm{l}$ of the Trans-Lentiviral Packaging kit (including 5 plasmids: pTLA1-PAK, pTLA1-ENZ, pTLA1-ENV, pTLA1-TOFF and pTLA1-TAT/REV) using calcium phosphate (105 $\mu \mathrm{l})$. At $48 \mathrm{~h}$ after transfection, the supernatant containing lentiviral particles was harvested and filtered through a $0.45 \mu \mathrm{m}$-diameter filter, and used to infect the SU-DHL-4 cells. The cells were selected using puromycin. The protein levels of IL-17R were evaluated by western blot analysis.

Assessment of apoptosis. The SU-DHL-4 cells from experiment 4 describe above were stained with propidium iodide (PI) and Annexin V-FITC reagent (BD Biosciences) following the manufacturer's instructions. The cells were then analyzed using flow cytometry. Annexin $\mathrm{V}^{+} \mathrm{PI}^{-}$cells were determined as apoptotic cells.

Statistical analysis. All analyses were performed using SPSS 17.0 software. Numerical data are presented as the means \pm standard deviation. Single-factor analysis of variance (one-way ANOVA), Student-Newman-Keuls/Dunnett's T3 tests (between each 2 set of groups) were used for comparisons among multiple groups. The Chi-square test was used for categorical data comparisons between 2 groups. Survival was estimated using the Kaplan-Meier method and the log-rank test. A P-value of 0.05 was considered to indicate a statistically significant difference.

\section{Results}

Rituximab increases IL-17A levels and the proportions of Th17 and IL-17+ Foxp $3^{+}$Treg cells in the PBMCs from patients with $D L B C L$. We examined the mechanisms through which rituximab affects the expression of IL-17A and its two associated secretory cells in patients with DLBCL by detecting the IL-17A levels and the proportions of Th17 and IL-17+Foxp3 ${ }^{+}$ Treg cells in the PBMCs by ELISA and FACS analysis, respectively. A total of 113 patients newly diagnosed with DLBCL and 20 healthy donors were divided into 6 groups, as described in the Materials and methods. Representative FACS plots of the Th17 and IL-17 ${ }^{+}$Foxp $3^{+}$Treg cells from each group are shown in Fig. 1A and B. The IL-17A levels and the proportions of Th17 and IL- $17^{+} \mathrm{Foxp}^{+}$Treg cells were significantly higher in the Ctrl, R-CHOP-CR and R-CHOP-NCR groups, compared with the DLBCL, CHOP-CR and CHOP-NCR groups (Fig. 1C-E), implying that rituximab elevated the IL-17A levels and the differentiation of its two associated secretory cells. The IL-6 levels in the R-CHOP-CR and R-CHOP-NCR groups were also significantly increased compared with those in the DLBCL, CHOP-CR and CHOP-NCR groups (Fig. 1F). The TGF- $\beta$ levels were higher in the DLBCL group than in the Ctrl group (Fig. 1H). Rituximab had no significant effect on the IL-21 and TGF- $\beta$ levels in any group (Fig. 1G and H).

Rituximab increases IL-6 expression in DLBCL cell lines. Rituximab increased IL-6 expression in the PBMCs from patients with DLBCL (Fig. 1). To confirm this phenomenon and the cell source, we cultured the SU-DHL-4 cells with various concentrations of rituximab and analyzed the expression of IL-6 in the SU-DHL-4 cells. Rituximab markedly increased the protein and mRNA levels of IL-6 in the SU-DHL-4 cells in a concentration- 

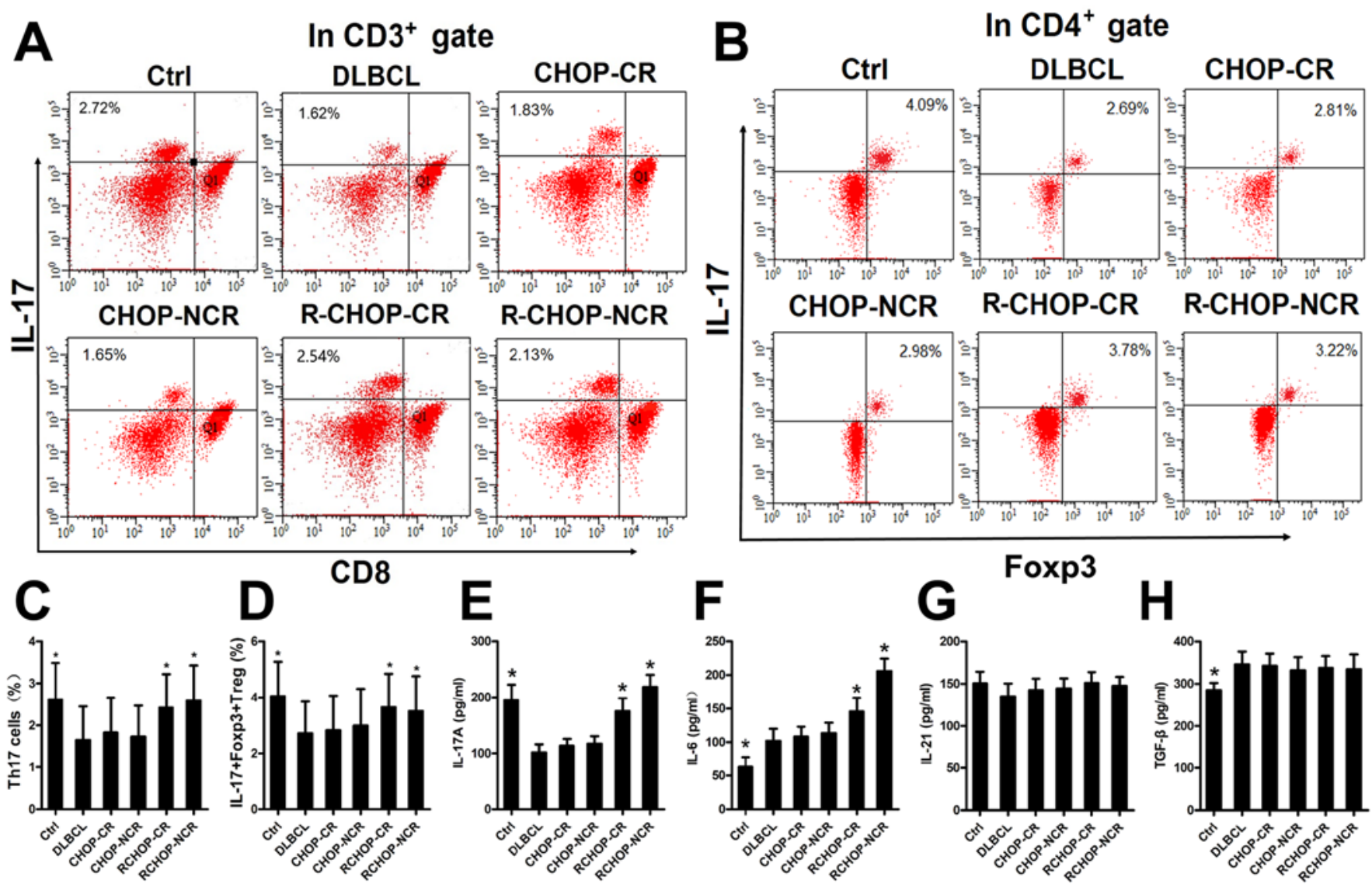

Figure 1. Rituximab elevates the level of IL-17A and the percentages of Th17 cells and IL-17+Foxp $3^{+}$Treg cells in the peripheral blood mononuclear cells (PBMCs) from patients with diffuse large B cell lymphoma (DLBCL). (A and B) Representative FACS plots of Th17 cells and IL-17 ${ }^{+}$Foxp3 ${ }^{+}$Treg cells in the PBMCs from each group. The numbers displayed are the percentages of Th17 cells and IL-17 Foxp3 ${ }^{+}$Treg cells. (C and D) Graphs of the Th17 cells and IL- $17^{+}$Foxp $3^{+}$Treg cell percentages in each group. (E-H) Graphs of the levels of IL-17A, IL-6, IL-21 and TGF- $\beta$ in each group. Error bars represent standard deviation (SD). Significance was determined using single-factor analysis of variance (one-way ANOVA) with Student-Newman-Keuls/Dunnett's T3 test (3 groups). ${ }^{*} \mathrm{P}<0.05$, compared with the DLBCL, CHOP-CR or CHOP-NCR group. CR, complete remission; NCR, no complete remission.

dependent manner (Fig. 2A-C). Typical western blots of IL-6 protein are shown in Fig. 2A. IL-6 in the culture supernatants was also significantly elevated in a rituximab concentrationdependent manner, as detected by ELISA (Fig. 2D).

Rituximab upregulates IL-17A levels and the proportions of Th17 and $I L-17^{+}$Foxp $^{+}$Treg cells in vitro. IL-6 enhances the differentiation of Th17 cells and IL- $17^{+}$Foxp $3^{+}$Treg cells together with TGF- $\beta$ (12). As demonstrated above, rituximab elevated IL-6 expression in DLBCL cells and in PBMCs from patients with DLBCL, and that TGF- $\beta$ levels were increased in patients with DLBCL (Fig. 1H). We therefore hypothesized that rituximab would increase the proportions of Th17 and IL- $17^{+}$Foxp $3^{+}$Treg cells and upregulate the IL-17A levels in the SU-DHL-4 cells and PBMCs in vitro. To examine this hypothesis, we cultured the cells as described in the Materials and methods and analyzed the cells and supernatants by FACS analysis and ELISA. Representative FACS plots of Th17 and IL-17 $7^{+}$Foxp $3^{+}$Treg cells from each group are shown in Fig. 3A and B. Rituximab had no effect on the proportions of Th17 and IL- $17^{+} \mathrm{Foxp} 3^{+}$Treg cells or on the IL-17A levels in the PBMCs cultured without the SU-DHL-4 cells (Fig. 3C-E, bars a and b); however, both secretory cell populations and IL-17A expression levels were increased in the presence of the SU-DHL-4 cells (Fig. 3C-E, bars d and e). This upregulation was significantly enhanced by exogenous IL-6 (Fig. 3C, bars c and e; D, bars c and f; and E, bars c and f) and abolished by aIL-6 (Fig. 3C-E, bar g).

IL-17A suppresses p53 expression in the DLBCL cell lines. IL-17A has been reported to promote the growth of DLBCL (20), although the mechanism involved remain elusive. p53 is a tumor suppressor protein, and we have previously demonstrated that IL-17 suppressesp53 expression and induces the radiation resistance of $\mathrm{k} 1106 \mathrm{~B}$ cell lymphoma cells (21). We thus hypothesized that rituximab-induced IL-17A expression may suppress p53 expression in the SU-DHL-4 cells. Co-culture experiments demonstrated that rituximab alone did not affect p53 expression in the SU-DHL-4 cells (Fig. 4A and $\mathrm{B}$, bars a and b); however, p53 expression was significantly decreased in the SU-DHL-4 cells co-cultured with PBMCs and rituximab (Fig. 4A and B, bar c). To determine whether IL-17A is required for this p53-suppressing process, we added a neutralizing anti-IL-17A antibody to the co-cultures, which resulted in a significantly increased p53 expression in the SU-DHL-4 cells (Fig. 4 and B, bar d). By contrast, exogenous IL-17A significantly decreased the expression of p53 in the SU-DHL-4 cells (Fig. 4A and B, bars e and f). Representative western blots of p53 protein are shown in Fig. $4 \mathrm{C}$. 
A
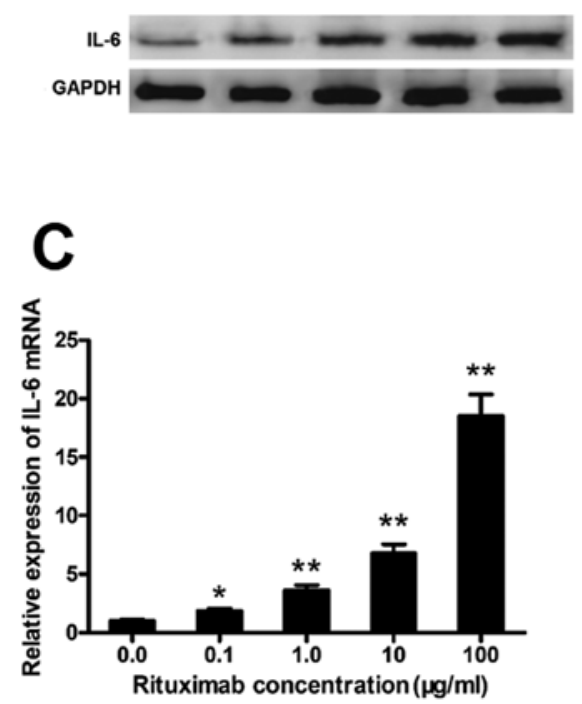
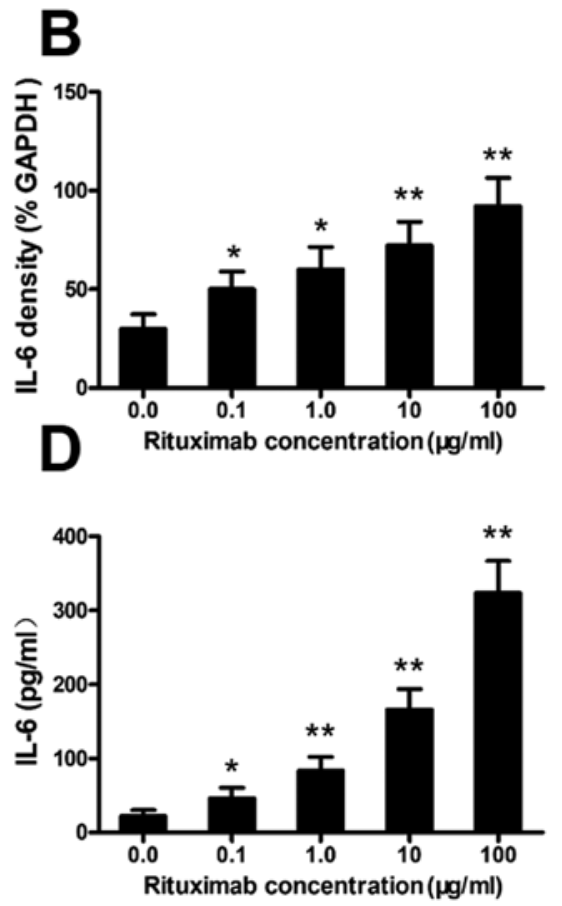

Figure 2. Rituximab increases IL-6 expression in diffuse large B cell lymphoma (DLBCL) cells. SU-DHL-4 cells were co-cultured with rituximab as described in the Materials and methods; the concentration of rituximab is denoted on the x-axis. The cellular extracts and supernatants were analyzed by RT-qPCR, western blot analysis and ELISA. (A) Representative western blots of IL-6 protein from the SU-DHL-4 cells. (B-D) Graphs of the protein levels of IL-6 (western blot analysis), IL-6 mRNA and IL-6 protein (ELISA). Error bars represent standard deviation (SD). Significance was determined using single-factor analysis of variance (one-way ANOVA) with Student-Newman-Keuls/Dunnett's T3 test (3 groups). ${ }^{*} \mathrm{P}<0.05$ and ${ }^{* *} \mathrm{P}<0.01$, compared with the $0.0 \mu \mathrm{g} / \mathrm{ml}$ group. The data are from 1 of 3 independent experiments.

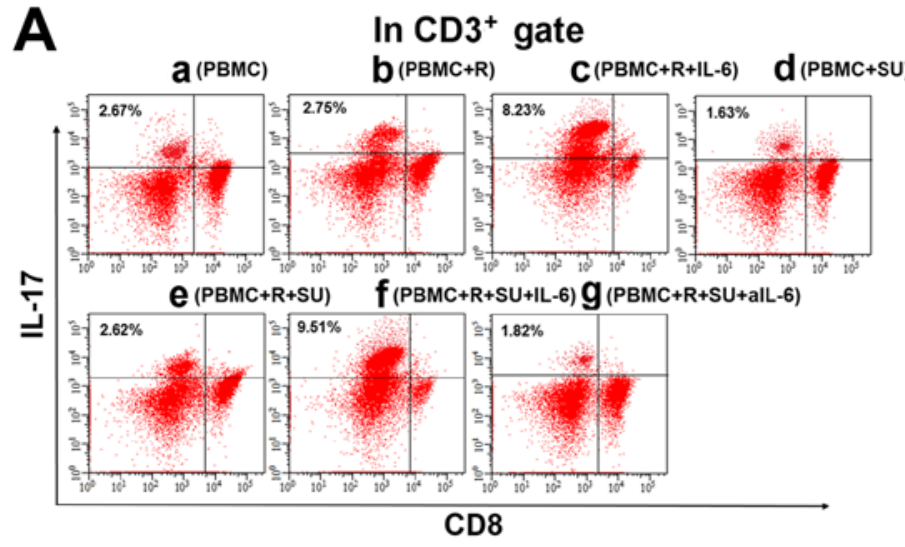

C

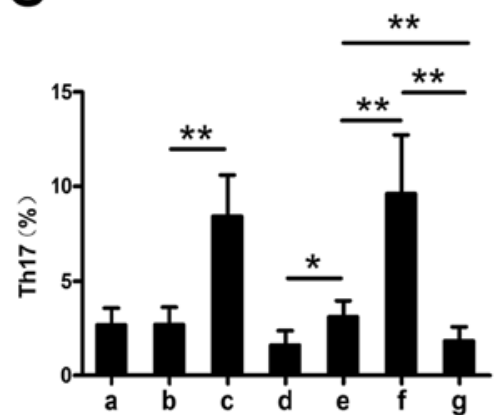

D

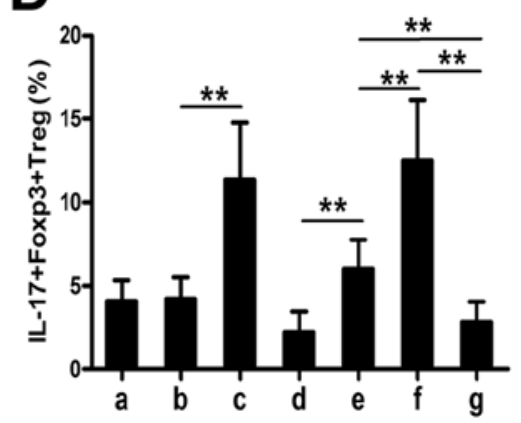

B In $\mathrm{CD}^{+}$gate

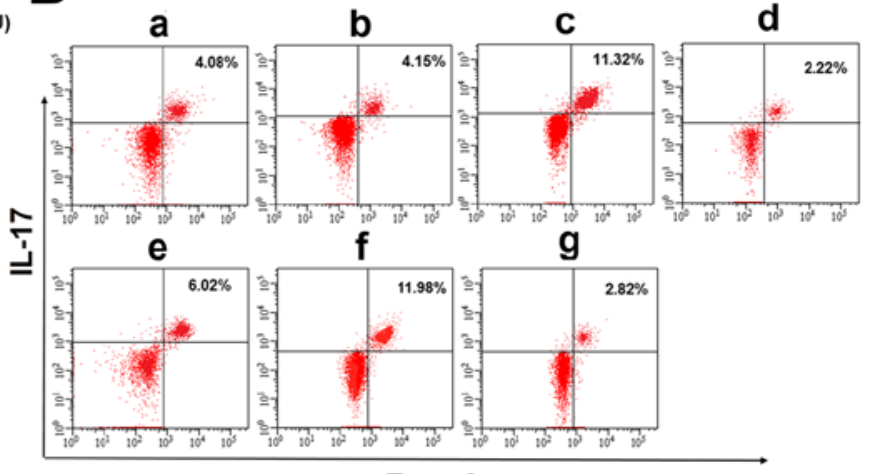

Foxp3

E

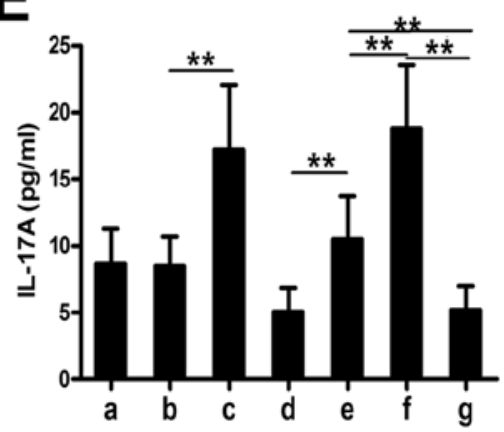

Figure 3. Rituximab upregulates the level of IL-17A and the percentages of Th17 cells and IL-17+Foxp $3^{+}$Treg cells in vitro. Co-cultures under 7 different conditions as described in the Materials and methods were defined as groups a-g. (A and B) Representative FACS plots of Th17 cells and IL-17 $7^{+}$Foxp $3^{+}$Treg cells in the co-cultures from each group. The numbers displayed are the percentages of Th17 cells and IL-17 ${ }^{+}$Foxp3 $3^{+}$Treg cells. (C-E) Graphs of the Th17 cells andIL-17+Foxp3 ${ }^{+}$Treg cell percentages, and IL-17A in each group. The plots and bars in (B-E) are labeled in the same manner (groups a-g) as in (A); groups a-g in (B-E) represent the same groups as those in (A). Error bars represent standard deviation (SD). Significance was determined using single-factor analysis of variance (one-way ANOVA) with Student-Newman-Keuls/Dunnett's T3 test ( 3 groups). ${ }^{*} \mathrm{P}<0.05$ and ${ }^{* *} \mathrm{P}<0.01$. The data are from 1 of 3 independent experiments. SU, SU-DHL-4 cells; R, rituximab; aIL-6, neutralizing antibody to IL-6. 


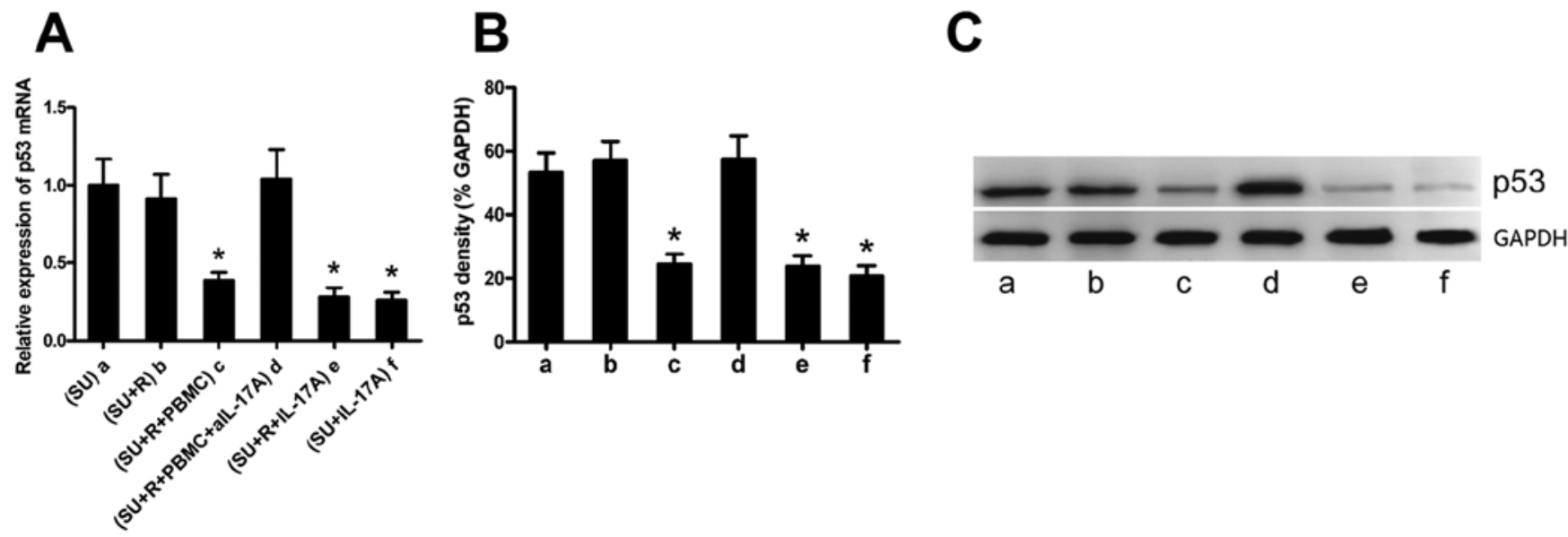

Figure 4. IL-17A suppresses p53 expression in DLBCL cells. The SU-DHL-4 cells were co-cultured under 6 different conditions as described in the Materials and methods and defined as groups a-f. (A and B) Graphs of the mRNA and protein levels of p53 RT-qPCR and western blot analysis, respectively). (C) Representative western blots of p53 protein. The plots and bars in (B and C) are labeled in the same manner (groups a-g) as in (A); groups a-g in (B and C) represent the same groups as those in (A). Error bars represent standard deviation (SD). Significance was determined using single-factor analysis of variance (one-way ANOVA) with Student-Newman-Keuls/Dunnett's T3 test ( 3 groups). $\mathrm{P}<0.05$ and ${ }^{* *} \mathrm{P}<0.01$, compared with group a. The data are from 1 of 3 independent experiments. SU, SU-DHL-4 cells; R, rituximab.

IL-17A prevents rituximab-induced $S U$-DHL-4 cell apoptosis and promotes $S U-D H L-4$ cell proliferation. The above-mentioned results suggest that IL-17A may promote SU-DHL-4 cell growth (Fig. 4), in accordance with previous findings (20). To examine this hypothesis, we cultured IL-17R-KD and wild-type SU-DHL4 cells with rituximab in the presence of various concentrations of IL-17A $(0-10 \mathrm{ng} / \mathrm{ml})$, and then analyzed the cells by FACS analysis and CCK- 8 assay. The frequency of apoptotic wild-type SU-DHL-4 cells was markedly suppressed by IL-17A in a concentration-dependent manner (Fig. 5A and B). We successfully knocked down IL-17R expression in the SU-DHL-4 cells using lentiviral-mediated shRNA, resulting in the significant down-regulation of IL-17R protein levels in the SU-DHL-4 cells (Fig. 5C). IL-17A (10 ng/ml) had no effect on the frequency of apoptotic IL-17R-KD SU-DHL4 cells (Fig. 5A and B) compared to the control $(10 \mathrm{ng} / \mathrm{ml}$ IL-17A). Furthermore, the proliferation rate of wild-type SU-DHL-4 cells, but not that of IL-17R-KD SU-DHL4 cells, was increased in an concentration-dependent manner by IL-17A (Fig. 5D).

Increased expression of IL-17A in PB predicts a poorer survival of patients with $D L B C L$. We investigated the association betweenIL-17A expression in PB from patients with DLBCL and their prognosis. We detected the IL-17A levels in PB from 73 patients with DLBCL prior to treatment with $\mathrm{R}$-CHOP regimens. The patients were separated into 2 groups according to the median PB level of IL-17A $(54.18 \mathrm{pg} / \mathrm{ml})$. There was no significant difference in the baseline clinical characteristics between the 2 groups (Table II). Survival analysis revealed that patients with high IL-17A levels had a significantly poorer progression-free survival (Fig. 6A) and overall survival (Fig. 6B) compared with the low IL-17A expression group $(\mathrm{P}=0.020$ and $\mathrm{P}=0.022$, respectively).

Mechanistic outline of RR in DLBCL. Based on the abovementioned results, we summarized the mechanistic outline

Table II. Baseline clinical characteristics of patients with DLBCL with varying IL-17A expression levels.

\section{IL-17A in peripheral blood}

Variable

Low $(n=42)$ $\operatorname{High}(\mathrm{n}=31)$

Age (years)
$<50$
$\geq 50$

P-value

Sex

Male

Female

P-value ${ }^{\mathrm{a}}$

Ann Arbor stage

I-II

III-IV

P-value ${ }^{a}$

IPI score ${ }^{\mathrm{c}}$

$1-3$

4-5

P-value ${ }^{a}$
15

27

0.807

26

16

0.633

17

25

0.231

24

19

18

0.812

10 21
DLBCL, diffuse large B cell lymphoma; ${ }^{a} \mathrm{Chi}$-square test; ${ }^{\mathrm{b}} \mathrm{Ann}$ Arbor stage according to Ann Arbor-Cotswald staging (1989). 'IPI score, International Prognostic Index score.

of RR in DLBCL in Fig. 7. Rituximab induces DLBCL cells to secrete IL-6, which promotes the differentiation of Th17 and IL- $17^{+}{ }^{+}{ }_{0 x p} 3^{+}$Treg cells from $\mathrm{CD} 4^{+} \mathrm{T}$ cells, and these two types of cells then secrete IL-17A. IL-17A prevents rituximab-induced apoptosis and promotes the proliferation of DLBCL cells by suppressing p53 expression. 
A Concentration of IL-17A $(\mathrm{ng} / \mathrm{ml})$
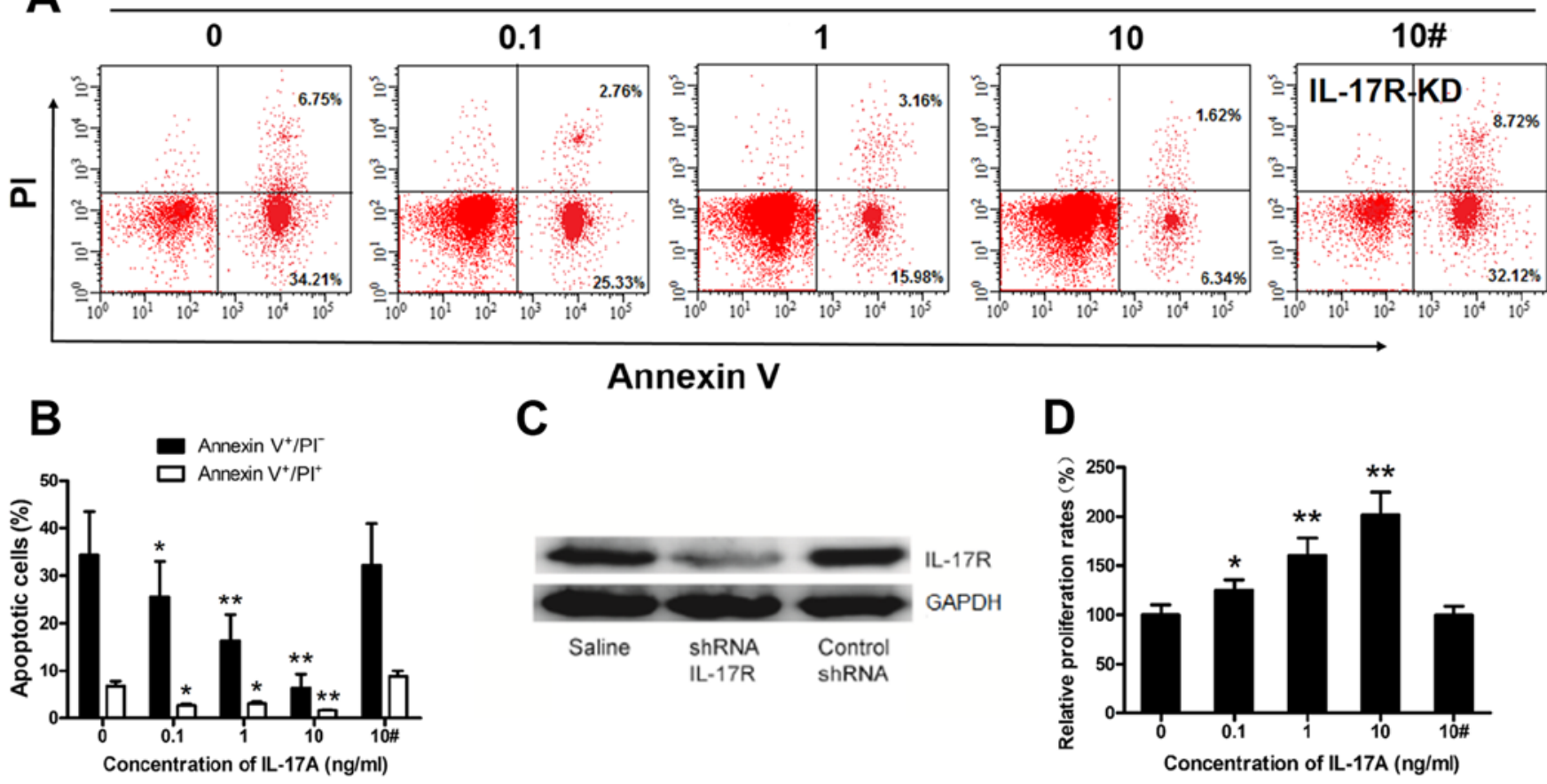

Figure 5. IL-17A prevents rituximab-induced SU-DHL-4 cell apoptosis and promotes SU-DHL-4 cell proliferation. Wild-type and IL-17 receptor-null SU-DHL-4 cells were co-cultured with rituximab $(100 \mu \mathrm{g} / \mathrm{ml}$ ) and various concentrations of recombinant IL-17A as denoted in the graphs. (A) Representative FACS plots of Annexin $\mathrm{V}^{+} / \mathrm{PI}^{-}$and Annexin $\mathrm{V}^{+} / \mathrm{PI}^{+} \mathrm{SU}-\mathrm{DHL}-4$ cells in the co-cultures of each group. (B) Graphs of the frequency of apoptotic cells. (C) Western blot analysis was used to determine the knockdown efficacy of IL-17R in the SU-DHL-4 cells. (D) Graph of the frequency of SU-DHL-4 cell proliferation rates in each group. In (B and D) the bar labeled 10\# indicates cells in which IL-17R was knocked down (IL-17R-KD). Error bars represent standard deviation (SD). Significance was determined using single-factor analysis of variance (one-way ANOVA) with Student-Newman-Keuls/Dunnett's T3 test (3 groups). "P<0.05 and ${ }^{* *} \mathrm{P}<0.01$, compared with the $0 \mathrm{ng} / \mathrm{mlgroup}$. The data are from 1 of 3 independent experiments.
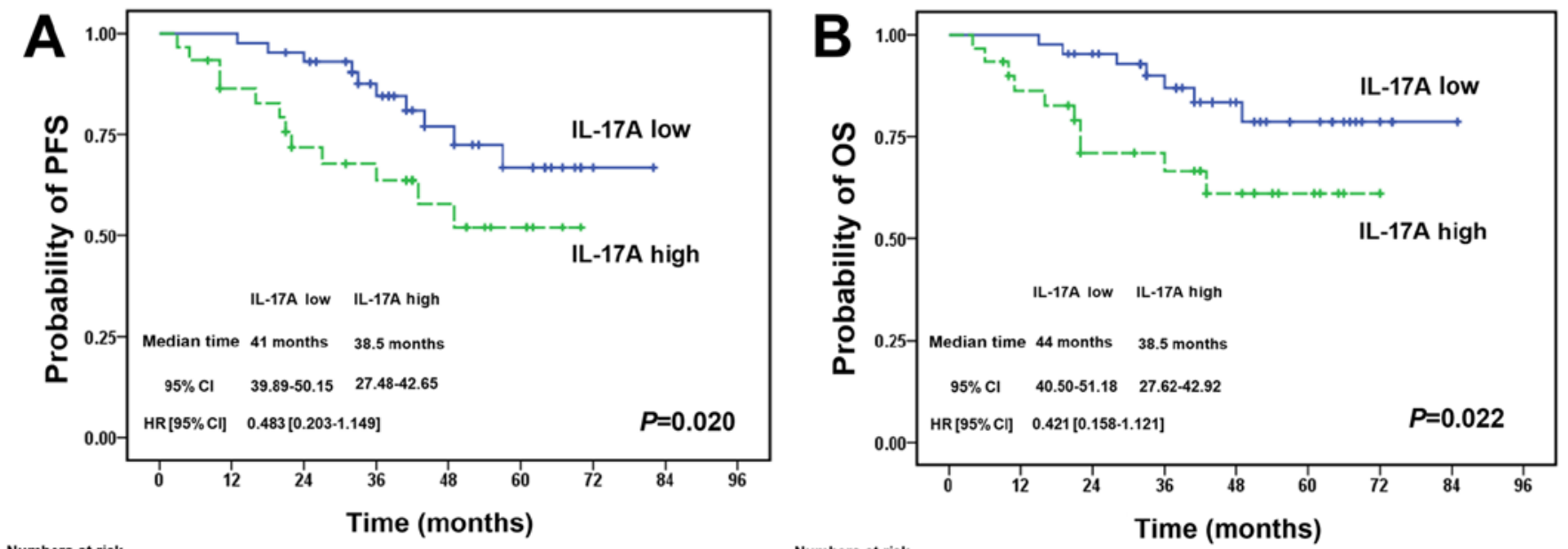

$\begin{array}{cccccccccc}\text { Numbers at risk } & & & & & & & & \\ \text { IL-17A low } & 43 & 43 & 39 & 33 & 26 & 24 & 24 & 0 & 0 \\ \text { IL-17A high } & 30 & 24 & 18 & 15 & 14 & 13 & 0 & 0 & 0\end{array}$

$\begin{array}{cccccccccc}\text { Numbers at risk } & & & & & & & \\ \text { IL-17A low } & 43 & 43 & 40 & 34 & 27 & 26 & 26 & 26 & 0 \\ \text { IL-17A high } & 30 & 27 & 18 & 16 & 15 & 15 & 15 & 0 & 0\end{array}$

Figure 6. Increased expression of IL-17A in peripheral blood predicts a worse survival of patients with diffuse large B cell lymphoma (DLBCL). A total of 73 patients with DLBCL (prior to treatment with R-CHOP regimens) were divided into 2 groups according to the median level (54.18 pg/ml) of IL-17A in PB. (A and B) The progression-free survival and overall survival of patients with DLBCL were significantly decreased with the increased expression of IL-17A, as shown by Kaplan-Meier survival analysis plots $(\mathrm{P}=0.020$ and $\mathrm{P}=0.022)$. Significance was determined using the log-rank test. Hazard ratio and $95 \% \mathrm{CI}$ were calculated using the Cox regression.

\section{Discussion}

RR presents a challenge to clinical specialists by limiting and weakening the therapeutic efficacy of rituximab inpatients with DLBCL. However, the mechanisms responsible for of RR remains elusive (5). In the current study, we demonstrated that rituximab promoted the differentiation of Th17 and IL- $17^{+} \mathrm{Foxp} 3^{+}$Treg cells, and increased the secretion of IL-17A by elevating IL-6 levels, both in patients with DLBCL and in vitro. IL-17A suppressed p53 expression, leading to the 


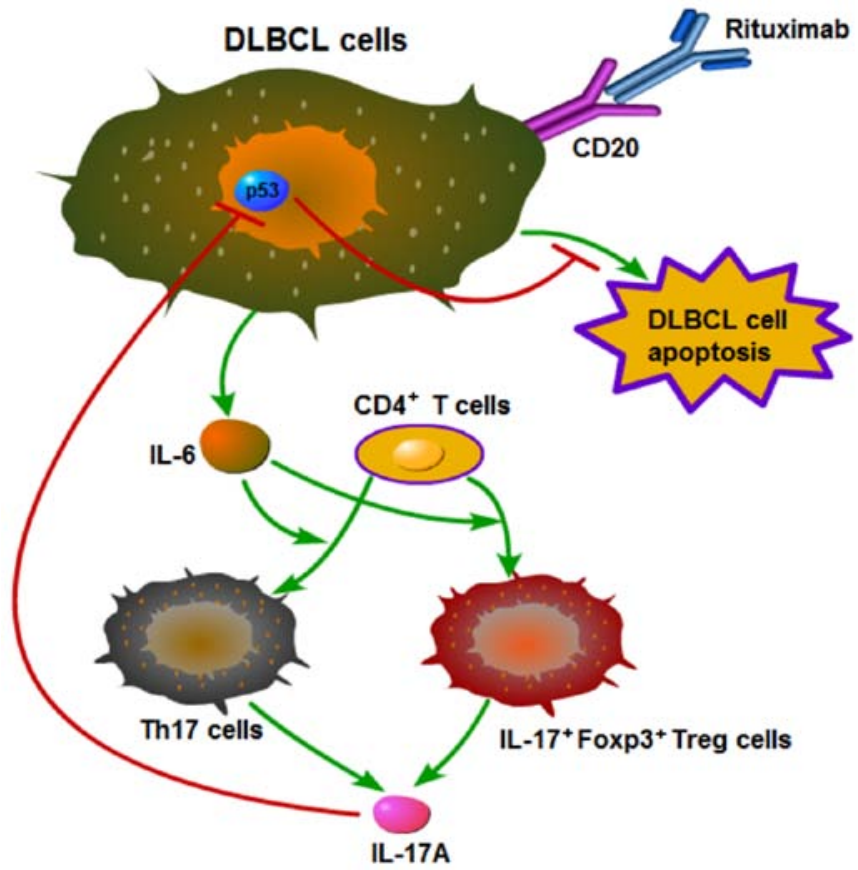

Figure 7. Mechanistic outline of rituximab resistance in diffuse large B cell lymphoma (DLBCL). Rituximab induces DLBCL cells to secrete IL-6, which promotes the differentiation of Th17 and IL- $17^{+} \mathrm{Foxp} 3^{+}$Treg cells from CD4 $\mathrm{T}$ cells, and these two types of cells then secrete IL-17A. IL-17A prevents rituximab-induced apoptosis and promotes the proliferation of diffuse large B cell lymphoma (DLBCL) cells by suppressing p53 expression.

inhibition of rituximab-induced apoptosis and enhanced the proliferation of DLBCL cells. Furthermore, high IL-17A levels in the PB of patients with DLBCL predicted a relatively poor prognosis.

We previously demonstrated that B-NHL cells secreted IL-6, which was upregulated by irradiation (21). Other studies have confirmed that rituximab induced IL- 6 production in human B cells in vitro (26) and elevated serum IL-6 levels in patients with DLBCL following chemotherapy $(23,24)$. By comparing patients treated with and without rituximab (R-CHOP and CHOP regimens), the current results indicated that rituximab significantly promoted IL-6 secretion in patients with DLBCL, and this finding was supported by in vitro experiments. Our results revealed that IL-6 levels were also elevated in patients in the R-CHOP-CR group. In addition, a previous study found that rituximab induced IL-6 production in human B cells (26); thus, we considered that human B cells and other cells apart from DLBCL cells secreted IL-6 following rituximab administration. Our results were thus in accordance with the above conclusions. High plasma IL-6 levels have been shown to be associated with poorer clinical outcomes following rituximab-combined therapy in patients with DLBCL (27), suggesting that IL-6 may be a potential therapeutic target in DLBCL. However, previous experimental data demonstrated that anti-IL-6 therapy was ineffective in irradiation-resistant lymphoma and myeloma cells (28). We thus speculated that increased IL-6 levels may play a role by influencing other cytokine networks or signaling pathways. Further studies are warranted in order to elucidate the mechanisms whereby increased IL- 6 influences the therapeutic effects of rituximab.
Previous studies have demonstrated that IL-17A plays a critical role in promoting the growth of germinal cell BDLBCL cells in vitro and in a mouse model (20), and in inhibiting irradiation-induced apoptosis of NHL cells (21), which are mainly derived from Th17 and IL- $17^{+}$Foxp $3^{+}$Treg cells. However, to the best of our knowledge, no previous studies have focused on the effects of rituximab on these two cell types and their associated cytokines in DLBCL patients or in vitro. Yin et al found that PBMC Th1 and Th2 cells from patients with DLBCL were influenced by the presence or absence of rituximab in the chemotherapy regimen, which was also related to the patients' response to treatment (29). Two previous studies have both shown that a low level of circulating Treg cells predicts a poor prognosis in patients with DLBCL $(30,31)$; however, to the best of our knowledge, no studies to date have determined whether rituximab affects Th17 cell differentiation and IL-17 levels in patients with DLBCL.T cells present developmental plasticity in the tumor microenvironment (13). As we speculated, our results provide the first evidence to indicate that rituximab increases the proportions of Th17 and IL- $17^{+}$Foxp $3^{+}$Treg cells, and increases IL-17A levels in vivo and in vitro, probably as a result of increased IL- 6 and TGF- $\beta$ levels. These effects may be ascribed to the plasticity of $\mathrm{CD} 4^{+} \mathrm{T}$ cell differentiation.

In this study, increased IL-6 levels induced the differentiation of Th17 cells, which secrete IL-17A. Conversely, other studies have shown that rituximab inhibits Th17 cells and IL-17A expression in anti-neutrophil cytoplasmic antibodyassociated vasculitis and primary Sjogren's syndrome $(32,33)$. We therefore consider that rituximab may affect Th17 and IL- $17^{+}$Foxp $3^{+}$Treg cells and IL-17A levels differently in NHL and in non-malignant B cell-associated immunological diseases. Lymphoma B cells exhibit an aberrant expression of CD70, CD80 or CD86 compared with normal B cells, and these costimulatory molecules interact with their ligands (CD27 or CD28) to play an important role in T cell differentiation and development (34). Lymphoma B cells have also been shown to upregulate Treg cells and inhibit Th17 cells by the above-mentioned CD27-CD70 or CD28-CD80/86 interactions between lymphoma cells and $\mathrm{CD}^{+} \mathrm{T}$ cells (18). We hypothesized that rituximab deleted lymphoma $\mathrm{B}$ cells and abolished these costimulatory molecule interactions, and increased the expression of Th17 cells. Moreover, we demonstrated that patients with DLBCL had higher TGF- $\beta$ levels and that rituximab increased IL-6 levels in DLBCL cells, suggesting that IL- 6 and TGF- $\beta$ may plastically promote Foxp $3^{+}$Treg cells to secrete IL-17A and thereby upregulate IL- $17^{+}$Foxp $3^{+}$Treg cell development.

The anticancer or cancer-promoting effects of IL-17A remain controversial, and may depend on the type of cancer or the functions of immune cells and related cytokines in the tumor microenvironment (13). A number of studies have suggested that IL-17A can promote the growth of many types of tumor (35-37). Ferretti et al demonstrated that IL-17A boosted the growth of human germinal center-derived B cell NHL in vitro and in a mouse model by promoting tumor cell proliferation and neo-angiogenesis (20). Having demonstrated that rituximab promoted IL-17A levels by inducing IL-6 expression both in vivo and in vitro, we also examined the effects of IL-17A on the development of DLBCL cells and showed that IL-17A boosted their proliferation. Rituximab 
is known to induce DLBCL cell apoptosis, and we therefore determined whether IL-17A affects rituximab-induced DLBCL cell apoptosis and the expression of the classical apoptosis regulator, p53. We found that rituximab-induced IL-17A expression prevented rituximab-induced DLBCL cell apoptosis, indicating that increased IL-17A thus promoted RR in patients with DLBCL. These conclusions are in agreement with the findings of our with our previous study (21) and with other published research (20).

p53 protein is an important tumor suppressor protein, and p53 dysfunction is involved in the pathogenesis of B-cell malignancies, including DLBCL $(38,39)$. The dysfunction of p53 inhibits DLBCL apoptosis and promotes DLBCL generation, progression and invasion (38). IL-17 has been reported to regulate matrix metalloproteinase- 9 mRNA levels in a p53-dependent manner and to promote lung tumor growth (35), and the data from a previous study indicated that high levels of IL-17 were associated with low levels of p53 in colorectal cancer (40). In accordance with the findings of previous studies, the results of the present study demonstrated that IL-17A suppressed the expression of p53 in DLBCL cells, which may partially account for the mechanism where by IL-17A inhibits the apoptosis of DLBCL cells.

We confirmed the association between IL-17A and the prognosis of patients with DLBCL treated with rituximab by analyzing the survival of 73 patients with DLBCL treated with the $\mathrm{R}-\mathrm{CHOP}$ regimen, and demonstrated that the increased expression of IL-17A in the PB of the patients predicted a poorer survival. IL-17A is therefore a prognostic factor in DLBCL. We previously identified interferon regulatory factor 8 expression in the tumor microenvironment as a prognostic factor for DLBCL (25), and other investigators have also found that non-tumor immune cell components in DLBCL lesions affected the efficacy of the R-CHOP regimen (17). However, serum IL-17A levels are more easily measured and are thus more useful in a clinical setting. In addition, this clinical result supports our hypothesis that increased IL-17A levels promote RR in patients with DLBCL. Patients with DLBCL usually receive rituximab combined chemotherapy for at least 4-6 months. Furthermore, the half-life of rituximab is long and it can persist for 3-6 months in vivo, suggesting that IL-17A may promote RR continuously for a prolonged period. Further clarification of the role of IL-17A in the pathogenesis of DLBCL may allow for the development of anti-IL-17A therapies to overcome RR.

Although the clinical part of this study was conducted retrospectively, we carried out in vitro experiments to confirm our conclusions. In the future, we aim to conduct a randomized controlled trial with a greater number of patients with DLBCL. We also aim to investigate other mechanisms whereby IL-17A may promote $\mathrm{RR}$, in addition to suppressing p53 expression in DLBCL cells. In addition, we aim to examine more DLBCL cell lines, such as ABC-subtype cell lines, in our future research.

In conclusion, in this study, we demonstrate that rituximab elevates IL-6 levels, which promote Foxp3 ${ }^{+}$Treg cells to secrete IL-17A, consequently promoting the differentiation

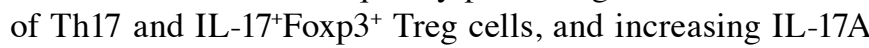
expression in patients with DLBCL, as well as in vitro. IL-17A prevents rituximab-induced apoptosis and promotes the proliferation of DLBCL cells by suppressing p53 expression (Fig. 7). Furthermore, increased PB levels of IL-17A predict an unfavorable prognosis inpatients with DLBCL. These results suggest that IL-17A promotes RR by suppressing p53 expression, and may thus be a useful prognostic factor for DLBCL. IL-17A may also be a potential future therapeutic target for RR.

\section{Acknowledgements}

Not applicable.

\section{Funding}

The present study was supported by the Guangzhou Planned Project of Science and Technology, China (grant nos. 201707010279, 201300000100 and 201704020105).

\section{Availability of data and materials}

The analyzed datasets generated during the study are available from the corresponding author on reasonable request.

\section{Authors' contributions}

WZ contributed to the experimental design and implementation, performed the experiments, drafted the manuscript, and performed data analysis. QL and YW conceived or designed the experiments, modified the manuscript. XX, ZZ, LY and ZY contributed to experiment implementation and data analysis. QD, HD, HX and ZX performed the experiments and data analysis. All authors have read and approved the final manuscript.

\section{Ethics approval and consent to participate}

This study was approved by the Ethics Committee of Guangzhou First People's Hospital (2014-SYL-034). Written informed consent was obtained from all participants or their families prior to obtaining the samples.

\section{Consent for publication}

Not applicable.

\section{Competing interests}

The authors declare that they have no competing interests.

\section{References}

1. Sehn LH and Gascoyne RD: Diffuse large B-cell lymphoma: Optimizing outcome in the context of clinical and biologic heterogeneity. Blood 125: 22-32, 2015.

2. Lenz G, Wright G, Dave SS, Xiao W, Powell J, Zhao H, Xu W, Tan B, Goldschmidt N, Iqbal J, et al; Lymphoma/Leukemia Molecular Profiling Project: Stromal gene signatures in largeB-cell lymphomas. N Engl J Med 359: 2313-2323, 2008.

3. Nakajima Y, Tomita N, Itabashi M, Miyashita K, Watanabe R, Miyazaki T, Tachibana T, Takasaki H, Kawasaki R, Tanaka M, et al: Analysis of outcomes in patients with supra-diaphragmatic vs infra-diaphragmatic diffuse large B cell lymphoma treated with R-CHOP therapy. Leuk Res 39: 198-203, 2015. 
4. Fowler NH: R2-CHOP vs R-CHOP for diffuse large B-cell lymphoma. Clin Adv Hematol Oncol 12: 608-610, 2014.

5. Rezvani AR and Maloney DG: Rituximab resistance. Best Pract Res Clin Haematol 24: 203-216, 2011.

6. Stolz C and Schuler M: Molecular mechanisms of resistance to Rituximab and pharmacologic strategies for its circumvention. Leuk Lymphoma 50: 873-885, 2009.

7. Bello C and Sotomayor EM: Monoclonal antibodies for B-cell lymphomas: Rituximab and beyond. Hematology (Am Soc Hematol Educ Program) 2007: 233-242, 2007.

8. Seyfizadeh N, Seyfizadeh N, Hasenkamp J and Huerta-Yepez S: A molecular perspective on rituximab: A monoclonal antibody for B cell non Hodgkin lymphoma and other affections. Crit Rev Oncol Hematol 97: 275-290, 2016.

9. Pavanello F, Zucca E and Ghielmini M: Rituximab: 13 open questions after 20 years of clinical use. Cancer Treat Rev 53: 38-46, 2017.

10. Iwakura Y, Ishigame H, Saijo S and Nakae S: Functional specialization of interleukin-17 family members. Immunity 34: 149-162, 2011.

11. Gaffen SL: Structure and signalling in the IL-17 receptor family. Nat Rev Immunol 9: 556-567, 2009.

12. Bettelli E, Carrier Y, Gao W, Korn T, Strom TB, Oukka M, Weiner HL and Kuchroo VK: Reciprocal developmental pathways for the generation of pathogenic effector TH17 and regulatory T cells. Nature 441: 235-238, 2006.

13. Hemdan NY: Anti-cancer versus cancer-promoting effects of the interleukin-17-producing T helper cells. Immunol Lett 149: 123-133, 2013

14. Du R, Zhao H, Yan F and Li H: IL- $17^{+} \mathrm{Foxp} 3^{+} \mathrm{T}$ cells: An intermediate differentiation stage between Th17 cells and regulatory T cells. J Leukoc Biol 96: 39-48, 2014.

15. Huang $\mathrm{C}$ and Fu ZX: Localization of IL-17+Foxp3 ${ }^{+} \mathrm{T}$ cells in esophageal cancer. Immunol Invest 40: 400-412, 2011

16. Li L and Boussiotis VA: The role of IL-17-producing Foxp3 ${ }^{+}$ $\mathrm{CD}^{+} \mathrm{T}$ cells in inflammatory bowel disease and colon cancer. Clin Immunol 148: 246-253, 2013.

17. Gomez-Gelvez JC, Salama ME, Perkins SL, Leavitt M and Inamdar KV: Prognostic impact of tumor microenvironment in diffuse large B-cell lymphoma uniformly treated with R-CHOP chemotherapy. Am J Clin Pathol 145: 514-523, 2016.

18. Yang ZZ, Novak AJ, Ziesmer SC, Witzig TE and Ansell SM: Malignant B cells skew the balance of regulatory $T$ cells and TH17 cells in B-cell non-Hodgkin's lymphoma. Cancer Res 69: 5522-5530, 2009.

19. Lu T, Yu S, Liu Y, Yin C, Ye J, Liu Z, Ma D and Ji C: Aberrant circulating Th17 cells in patients with B-cell non-Hodgkin's lymphoma. PLoS One 11: e0148044, 2016.

20. Ferretti E, Di Carlo E, Ognio E, Guarnotta C, Bertoni F, Corcione A,Prigione I, Fraternali-Orcioni G, Ribatti D, Ravetti JL, et al: Interleukin-17A promotes the growth of human germinal center derived non-Hodgkin B cell lymphoma. OncoImmunology 4: e1030560, 2015

21. Li Q, Xu X, Zhong W, Du Q, Yu B and Xiong H: IL-17 induces radiation resistance of $\mathrm{B}$ lymphoma cells by suppressing $\mathrm{p} 53$ expression and thereby inhibiting irradiation-triggered apoptosis. Cell Mol Immunol 12: 366-372, 2015.

22. Obenauf AC, Zou Y, Ji AL, Vanharanta S, Shu W, Shi H, Kong X Bosenberg MC, Wiesner T, Rosen N, et al: Therapy-induced tumour secretomes promote resistance and tumour progression. Nature 520: 368-372, 2015

23. Khan MA, Garg K, Bhurani D and Agarwal NB: Early manifestation of mild cognitive impairment in B-cell non-Hodgkin's lymphoma patients receiving CHOP and rituximab-CHOP chemotherapy. Naunyn Schmiedebergs Arch Pharmacol 389: 1253-1265, 2016.

24. Zimmer P, Mierau A, Bloch W, Strüder HK, Hülsdünker T, Schenk A, Fiebig L, Baumann FT, Hahn M, Reinart N, et al: Post-chemotherapy cognitive impairment in patients with B-cell non-Hodgkin lymphoma: A first comprehensive approach to determine cognitive impairments after treatment with rituximab, cyclophosphamide, doxorubicin, vincristine and prednisone or rituximab and bendamustine. Leuk Lymphoma 56: 347-352, 2015.
25. Zhong W, Xu X, Zhu Z, Du Q, Du H, Yang L, Ling Y, Xiong H and Li Q: Increased expression of IRF8 in tumor cells inhibits the generation of Th17 cells and predicts unfavorable survival of diffuse large B cell lymphoma patients. Oncotarget 8 : 49757-49772, 2017.

26. Jones JD, Hamilton BJ, Skopelja S and Rigby WF: Induction of interleukin- 6 production by rituximab in human B cells. Arthritis Rheumatol 66: 2938-2946, 2014.

27. Giachelia M, Voso MT, Tisi MC, Martini M, Bozzoli V, Massini G, D'Aló F, Larocca LM, Leone G and Hohaus S: Interleukin- 6 plasma levels are modulated by a polymorphism in the NF- $\mathrm{KB} 1$ gene and are associated with outcome following rituximab-combined chemotherapy in diffuse large B-cell non-Hodgkin lymphoma. Leuk Lymphoma 53: 411-416, 2012.

28. Gougelet A, Mansuy A, Blay JY, Alberti L and VermotDesroches C: Lymphoma and myeloma cell resistance to cytotoxic agents and ionizing radiations is not affected by exposure to anti-IL-6 antibody. PLoS One 4: e8026, 2009.

29. Yin Q, Chen L, Li Q, Mi R, Li Y, Wei X and Song Y: Changes of T-lymphocyte subpopulation and differential expression pattern of the T-bet and GATA-3 genes in diffuse large B-cell lymphoma patients after chemotherapy. Cancer Cell Int 14: 85, 2014.

30. Rusak M, Bołkun $Ł$, Chociej-Stypułkowska J, Pawlus J, Kłoczko J and Dąbrowska M: Flow-cytometry-based evaluation of peripheral blood lymphocytes in prognostication of newly diagnosed DLBCL patients. Blood Cells Mol Dis 59: 92-96, 2016.

31. Głowala-Kosińska M, Chwieduk A, Nieckula J, Saduś-Wojciechowska M, Grosicki S, Rusin A, Nowara E and Giebel S: Association of circulating regulatory $\mathrm{T}$ cell number with the incidence and prognosis of diffuse large B-cell lymphoma. Eur J Haematol 91: 122-128, 2013.

32. Pullerits R, Ljevak M, Vikgren J and Bokarewa M: Off-trial evaluation of the $\mathrm{B}$ cell-targeting treatment in the refractory cases of antineutrophil cytoplasmic antibodies (ANCA)-associated vasculitis: Long-term follow-up from a single centre. Scand J Immunol 76: 411-420, 2012

33. Ciccia F, Guggino G, Rizzo A, Alessandro R, Carubbi F, Giardina A, Cipriani P, Ferrante A, Cannizzaro A, Giacomelli R, et al: Rituximab modulates IL-17 expression in the salivary glands of patients with primary Sjögren's syndrome. Rheumatology (Oxford) 53: 1313-1320, 2014

34. Yang ZZ, Novak AJ, Ziesmer SC, Witzig TE and Ansell SM: $\mathrm{CD}^{+} 0^{+}$non-Hodgkin lymphoma B cells induce Foxp3 expression and regulatory function in intratumoral $\mathrm{CD} 4{ }^{+} \mathrm{CD} 25 \mathrm{~T}$ cells. Blood 110: 2537-2544, 2007.

35. Xu B, Guenther JF, Pociask DA, Wang Y, Kolls JK, You Z, Chandrasekar B, Shan B, Sullivan DE and Morris GF: Promotion of lung tumor growth by interleukin-17. Am J Physiol Lung Cell Mol Physiol 307: L497-L508, 2014.

36. Zhang Q, Liu S, Zhang Q, Xiong Z, Wang AR, Myers L, Melamed J, Tang WW and You Z: Interleukin-17 promotes development of castration-resistant prostate cancer potentially through creating an immunotolerant and pro-angiogenic tumor microenvironment. Prostate 74: 869-879, 2014.

37. Wu X, Zeng Z, Xu L, Yu J, Cao Q, Chen M, Sung JJ and Hu P: Increased expression of IL17A in human gastric cancer and its potential roles in gastric carcinogenesis. Tumour Biol 35: 5347-5356, 2014

38. Tessoulin B, Eveillard M, Lok A, Chiron D, Moreau P, Amiot M, Moreau-Aubry A, Le Gouill S and Pellat-Deceunynck C: p53 dysregulation in B-cell malignancies: More than a single gene in the pathway to hell. Blood Rev 31: 251-259, 2017.

39. Lu TX, Young KH, Xu W and Li JY: TP53 dysfunction in diffuse large B-cell lymphoma. Crit Rev Oncol Hematol 97: 47-55, 2016.

40. Radosavljevic G, Ljujic B, Jovanovic I, Srzentic Z, Pavlovic S, Zdravkovic N, Milovanovic M, Bankovic D, Knezevic M, Acimovic LJ, et al: Interleukin-17 may be a valuable serum tumor marker in patients with colorectal carcinoma. Neoplasma 57: $135-144,2010$

This work is licensed under a Creative Commons Attribution-NonCommercial-NoDerivatives 4.0 International (CC BY-NC-ND 4.0) License. 